\title{
MicroRNAs, Cellular Behavior, and Endometrial Cancer
}

\author{
Eric J. Devor, Ph.D. ${ }^{1}$
}

Key Words: microRNA, cancer, cellular behavior, dysregulation, endometrial cancer

\begin{abstract}
Endometrial cancer is the most common gynecological cancer and the fourth most common cancer in women worldwide. In spite of its' relative importance to overall morbidity among women, molecular research in endometrial cancers lags far behind other cancers such as breast and colorectal. Nowhere is this more true than in research in the newly emergent field of posttranscriptional gene regulation by small, regulatory RNAs, primarily microRNAs (miRNAs). Here, structure, biogenesis, and mode of action of miRNAs are presented along with a brief overview of the role of miRNAs in carcinogenesis and a review of the few miRNA studies in endometrial cancer carried out to date.

${ }^{1}$ Department of Obstetrics and Gynecology, University of lowa Carver College of Medicine, lowa City, IA
\end{abstract}

Introduction

In a now classic review paper, Hanahan and Weinberg ${ }^{1}$ outlined what they considered to be the hallmarks of cancer. These hallmarks, that are acquired by cancer cells, are 1 . self-sufficiency in growth signals, the ability of cancer cells to promote their own growth, 2 . insensitivity to anti-growth signals, the ability of cancer cells to ignore homeostatic signals, 3 . evasion of apoptosis, the ability of cancer cells to ignore programmed cell death, 4 . limitless replicative potential, the ability of cancer cells to grow unchecked, $5 . \quad$ sustained angiogenesis, the ability of cancer cells to supply themselves with resources such as oxygen and nutrients, and 6. tissue invasion and metastasis, the ability of cancer cells to colonize other regions of the body. Not all cancer cells will acquire these characteristics at the same rate nor will they acquire them in the same order nor will they acquire them by the same mechanisms thus making cancers a very heterogenous group of diseases with individual and quite variable characteristics. However, from the list of acquired

Please cite this paper as: Devor EJ. MicroRNAs, Cellular Behavior, and Endometrial Cancer. Proc Obstet Gynecol. 2010 Oct;1(2):Article 1[15 p.]. Available from: http://ir.uiowa.edu/pog/vol1/iss2/1/. Free full text article.

Corresponding author: Eric J. Devor, Ph.D., Department of Obstetrics and Gynecology, University of lowa Carver College of Medicine, 3234 MERF, lowa City, IA 52242, edevor@uiowa.edu

This is an Open Access article distributed under the terms of the Creative Commons Attribution 3.0 Unported License (http://creativecommons.org/licenses/by/3.0), which permits unrestricted use, distribution, and reproduction in any medium, provided the original work is properly cited. 
characteristics presented above it is abundantly clear that the one thing that cancer cells do have in common from the very beginning is that they do not behave the same way that non-cancer cells do.

Normal cells, whether they be skin cells, neurons, kidney, or uterus, maintain their individual integrity, respond to their micro- and macroenvironments, and interact with other cells according to a set of internally and externally driven programs designed to sustain equilibria that were established over more than three billion years of evolution. Cancer cells seem not to obey many of these rules, they create their own set of programs that ignore the established principles of cellular response and interaction. They are, in essence, an invasive species for which the equilibria of the environment in which they find themselves are irrelevant. Yet, cancer cells are not aliens that dropped in from an alternate universe. Indeed, cancer cells are ultimately all descended from perfectly normal cells that obeyed all of the rules. Thus, the rules that cancer cells follow are not written de novo but are, rather, re-written from the normal rules.

The rules of cellular behavior are enforced by a single primary agency. Most of the actions and reactions carried out in any cell are implemented by proteins. Cellular proteins are present in the cells in a bewildering array of sizes, functions, and amounts yet all of these proteins ultimately arise from the primary messages carried in the genes. The
DNA sequences that encode the proteins are first transcribed into an RNA message which is, in turn, translated into the specific amino acid sequence of a protein and this is done in a carefully managed amount necessary for the cell to function. The checks and balances on the amounts of the various proteins required for a specific cell to function reside at three levels. At the DNA level there are elegant feed back systems that determine the time, the place, and the amount of transcription of genomic DNA into RNA. At the protein level there is an equally elegant system in which the primary amino acid sequences of proteins are processed into mature proteins able to carry out their specific functions. This is accompanied by cell- and tissuespecific mechanisms for protein transport as well as protein-protein and protein-RNA interactions. Until recently, it was believed that these two levels of control were all that the cell had at its disposal. In the past few years we have become aware of a level of control that lies in between the two we knew. This began in 1993 in the laboratory of Victor Ambros with the chance discovery in the tiny worm Caenorhabtidis elegans of a very short RNA sequence that, instead of coding for a protein, was capable of regulating the translation of the messenger RNA of another gene into its protein. This was a completely unknown level of control, now called post-transcriptional gene regulation, which has been found to be a ubiquitous and powerful mechanism throughout both the animal and plant kingdoms. In human and other animal cells, the 
primary agent of this posttranscriptional gene regulation is the microRNA (miRNA). Here, we present the structure, biosynthesis, and mechanism of action of miRNAs, discuss the current level of understanding of the role of miRNAdirected gene regulation in cancer, and, finally, the status of miRNA research in endometrial cancers.

\section{miRNA structure, biosynthesis, and mode of action}

The discovery of miRNAs and the subsequent discovery of other small regulatory RNAs represent an entirely new arena in functional genomics involving the regulation of gene expression following DNA to RNA transcription. Since the first miRNA was identified in $1993^{2,3}$, thousands of these tiny (21-24nt) regulatory elements have been identified throughout the plant and animal kingdoms as well as in a number of viruses ${ }^{4}$. Recognition of the role of small regulatory RNAs in post-transcriptionally regulating genes involved in a host of cellular processes, including cellular differentiation, development, and apoptosis as well as pathogenesis, continues to expand ${ }^{5,6}$. One important aspect of this growing recognition of the role of small regulatory RNAs in cellular processes is that they themselves are precisely regulated through as yet unknown processes. It is clear, however, that small regulatory RNA expression varies enormously by tissue type, developmental stage, and by factors such as disease and external environmental stressors. Thus, the small RNA profile of any cell in any species at any particular stage of development or circumstance cannot be predicted but, rather, must be empirically determined. Moreover, it has become apparent that one miRNA can regulate the translation of many genes, that any one gene can be post-transcriptionally regulated by more than one miRNA, and that the specific mechanisms of miRNA/target mRNA interactions are complex well beyond simple antisense base-pair binding ${ }^{7-9}$.

MicroRNA biogenesis (figure 1) begins with the RNA polymerase II directed production of a primary RNA transcript (pri-miRNA) that can be several thousands of nucleotides in length and be either intragenic, lying in the DNA between genes, or intronic, lying in the non-coding DNA within genes. Primary miRNA transcripts are capped and polyadenylated in the same way as protein coding mRNA transcripts ${ }^{10}$. The pri-miRNA transcript contains within it one (usually) or more (rarely) sequences that form characteristic thermodynamically stable hairpin structures. This hairpin structure, called the precursor or premiRNA, typically ranges in size from 60 nt to 110nt (figure 1). These hairpin structures induce the formation of an RNA-protein complex, composed of the RNA hairpin, the RNase III endonuclease DROSHA, and a double-stranded RNA binding protein partner which in mammals is called DGCR8 ${ }^{11}$. The latter protein binds the pre-miRNA and DROSHA excises it from the primary transcript. The remaining RNA in the pri-miRNA transcript is 
simply recycled in the nucleus. Once excised, the pre-miRNA is handed off to another nuclear protein, a Ran transport receptor protein family

\section{Primary miRNA transcript (pri-miRNA)}

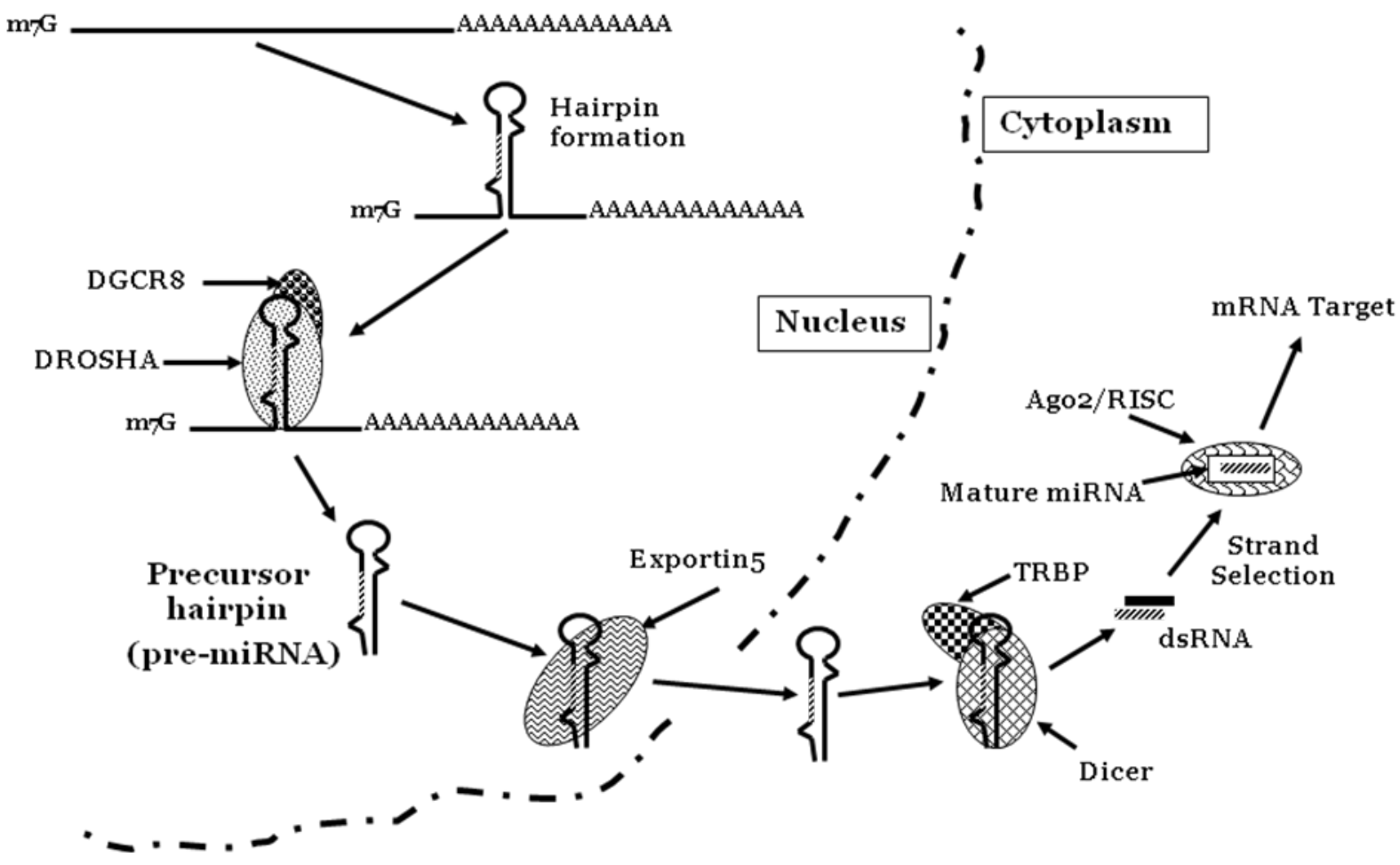

member called Exportin 5, which binds the hairpin and transports it from the nucleus to the cytoplasm ${ }^{12}$.

Figure 1. The pathway of microRNA biogenesis. A primary RNA transcript is generated by RNA polll which then capped and polyadenylated (pri-miRNA). Within this transcript a thermodynamically stable hairpin structure is formed (pre-miRNA). The hairpin structure is excised from the primary transcript through the combined action of the enzyme DROSHA and its partner DGCR8. This hairpin is passed off to a transport protein, Exportin 5, which ferries the hairpin from the nucleus to the cytoplasm. Once in the cytoplasm, the hairpin is bound by the enzyme Dicer and its partner TRBP which excises the small double-stranded RNA containing the mature miRNA and the star sequence. This is then handed off to an Argonaute protein, Ago2, which selects the mature miRNA strand and packages it into the RNA-induced silencing complex, RISC, for transport to its eventual mRNA target.

In the cytoplasm the pre-miRNA hairpin is recognized as a doublestranded RNA which induces a second RNase III endonuclease, called Dicer, which binds to the hairpin in association with another protein called TRBP (TAR RNA binding protein) and cleaves it in a precise manner to produce a small (21nt - 23nt) double-stranded molecule which is composed of the mature miRNA effector and its complement called the star, or miRNA*, sequence ${ }^{13,14}$. Conventional nomenclature refers to a microRNA as miR. This is preceded by the species from which it comes, for example Hsa for Homo sapiens, $M m u$ for the mouse species Mus musculus, and Cfa for the dog 
Canis familiaris. It is then followed by a number that is assigned by the curatorial miRNA database, miRBase, at the University of Manchester in the United Kingdom ${ }^{4}$. Many miRNAs are found in multiple species and some are quite ancient so such a nomenclature avoids a great deal of confusion. In practice, however, most miRNA are simply referred to as $m i R-x x x$ and they will be in this paper with the understanding that, for example, the designation miR-21 or miR-200c actually refers to hsa-miR-21 or hsamiR-200c.

The double-stranded RNA generated by Dicer/TRBP is nearly always imperfectly complementary, with one or more mismatched bases being the rule, and displays a 2nt 3' overhang on both strands (figure 1). This double-stranded molecule is then handed off to an Argonaute protein, called AGO2 in mammals, which is the primary component of a ribonucleoprotein complex called RISC (RNA induced silencing complex). In RISC the AGO2 protein selects the mature miRNA strand and cleaves the star strand. At this point, RISC transports the mature miRNA sequence to its target mRNA. Mature miRNAs bind in an antisense orientation to one or more locations in the 3' UTR of the mRNA where the result is either to suppress (usually) or eliminate (rarely) mRNA translation into an amino acid sequence. Complementarity of the mature miRNA sequence to its mRNA target sequence is nearly always imperfect. Indeed, it is believed that the mismatches in the miRNA/mRNA complementary sequences are necessary. There is one piece of the miRNA sequence that is quite specific, however. The 8nt RNA sequence from position two through position nine from the 5' end is called the seed and it is the seed that principally determines recognition of the miRNA and its mRNA target ${ }^{5,8}$. It is through this mechanism that cells can regulate protein production even if the original DNA encoding that protein is fully transcribed into RNA.

\section{miRNAs and Cancer: Oncogenes and Suppressors}

The rapidly expanding role of miRNAs in cancer has been documented in a number of excellent recent reviews ${ }^{15-17}$. What is clear from these and other reviews is that miRNAs can function as both tumor suppressors and as oncogenes depending upon their targets. There are currently more than 700 human microRNAs archived in miRBase. Of these, only a handful have yet to be fully evaluated for their potential involvement in cancer. However, Calin et al. ${ }^{18}$ showed that more than half of the then known human miRNAs were located in cancerassociated genome regions or in fragile sites. Over the past few years, a number of specific human miRNAs have been shown to be differentially expressed in specific cancers. For example, Ciafre et al. ${ }^{19}$ showed that several miRNAs (notably miR-21, $m i R-221$, and $m i R-181)$ are significantly over- or underexpressed in primary glioblastoma. Other examples include differential expression of miR-15 and miR-16 in $\mathrm{CLL}^{20}$, a number of miRNAs in 
hepatocellular carcinoma ${ }^{21}$, let-7 and the miR-17-92 cluster in lung cancer $^{22,23}, m i R-155$ and the miR-1792 cluster in lymphomas ${ }^{24,25}$; a large number of miRNAs in clear cell renal cell cancers $^{26}$ and numerous miRNAs in $\mathrm{Gl}$ cancer ${ }^{27}$.

A very nice compilation of the most recent findings regarding specific miRNAs was presented by Spizzo et al. $^{28}$. They note that the functional consequences of substantial changes in the expression of miRNAs, either up or down relative to non-cancer cells, are only just starting to come to light. Overexpression of the miRNA miR21 can induce self-sustaining growth signals in cells, the first hallmark of cancer proposed by Hanahan and Weinberg ${ }^{1}$ as discussed above. Insensitivity to anti-growth signals, the second hallmark of cancer, has been achieved through inhibition of E2F transcription factors in response to overexpression of the miR-17 miRNA cluster on human chromosome $13 \mathrm{q} 31.1$ as well as through overexpression of the miR106b-25 cluster located on human chromosome 7q22.1. Spizzo et al. note that specific E2F growth factors are inhibited by specific members of these miRNA clusters, for example E2F2 and E2F3 are inhibited by miR20a, a member of the miR-17 cluster, and expression of E2F1 is inhibited by both miR-17-5p and miR-20a from the miR-17 cluster and by $m i R-106 b$ and $m i R-92$ of the $m i R$ $106 \mathrm{~b}$ cluster. Alteration of apoptosis pathways potentially leading to evasion can be achieved through miRNAs targeting either anti- apoptotic proteins, such as BCL2 and MCL1 by the miR-15/16 cluster, or pro-apoptotic proteins, such as TP53BP1 by miR-155. Unrestricted proliferation can be induced through down-regulation of $m i R-138$ which leads to repressed translation of telomerase reverse transcriptase or TERT. Sustained angiogenesis is well known to be directly caused by hypoxia and the hypoxia-inducible factor, HIF-1, which, in turn, activates several miRNAs including miR-30b, miR-93, miR-181b, and, in particular, miR-210.

As noted, whether or not a specific miRNA acts as a suppressor or as an oncogene relates to the target, or targets, of that miRNA. As a consequence of target specificity and the regulatory mechanisms involved, a miRNA can be an oncogene in one tumor and a tumor suppressor in another ${ }^{28}$. Two genes, HER2 and HER3, significantly associated with breast cancer survival, are suppressed by one of the human miR-125 family ${ }^{29}$ but both miR-125a and miR-125b target other genes where their effects are likely to be oncogenic. The previously mentioned miR-17-92 polycistronic miRNA cluster on human chromosome $13 q 31.3$ has been implicated as oncogenic in a number of cancers ${ }^{30}$ but $m i R-17$ has an antitumorigenic effect in breast cancer. Other such Jekyll and Hyde miRNAs include members of the let-7 family and the miR-29 family. Clearly, the role of miRNAs in cancer is and will continue to be diverse and as unpredictable as the genes they target. 


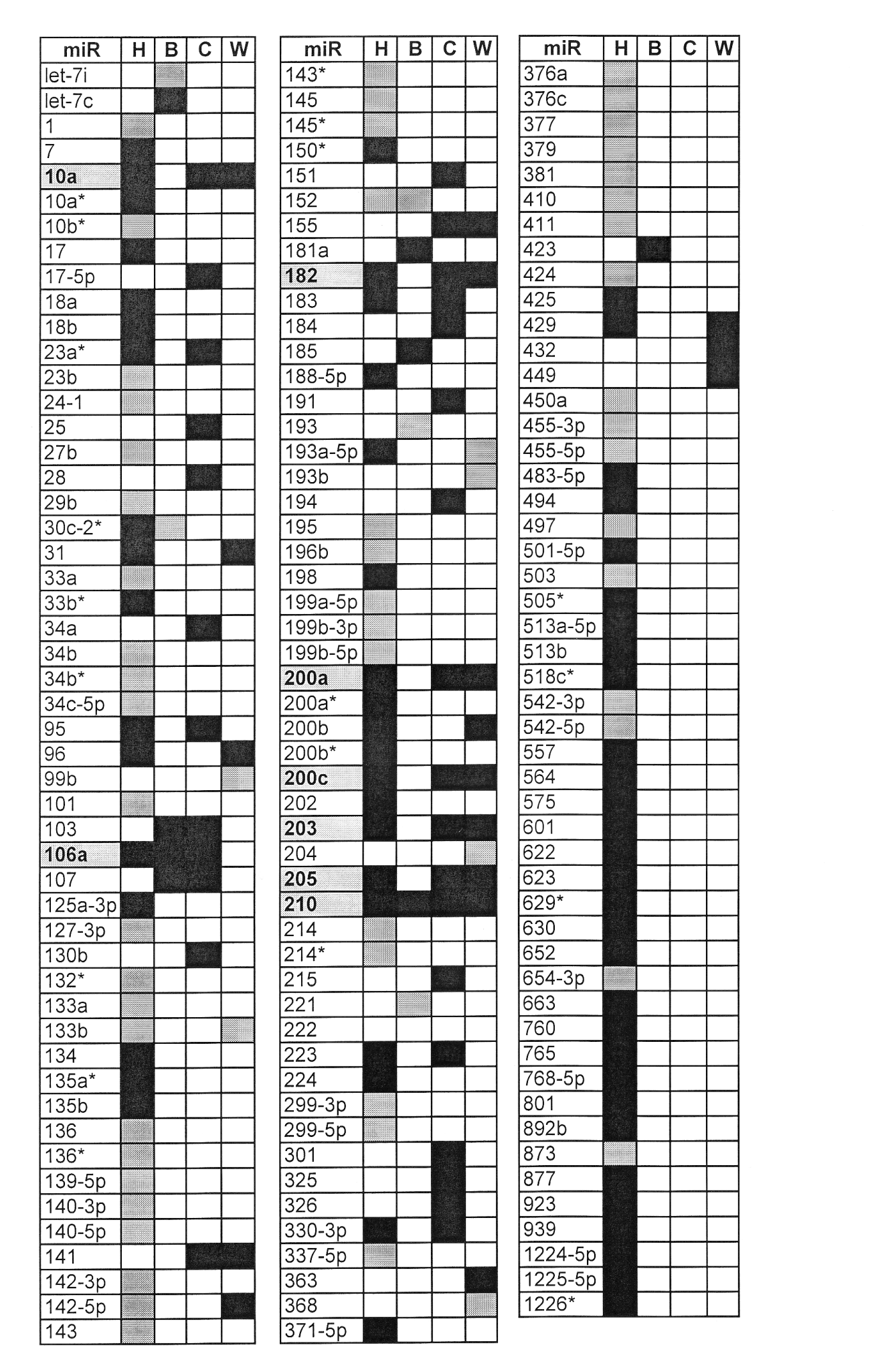

Figure 2. The miRNA landscape of endometrial cancer. microRNAs reported to be over-expressed in endometrial cancers compared to normal endometrium are shown as black squares while those reported to be under-expressed in endometrial cancers compared to normal endometrium are shown as grey squares. The eight miRNAs reported in at least three of the four surveys are bolded. The four extant miRNA surveys are; H (Hiroki et al., 2009), B (Boren et al., 2008), C (Chung et al., 2009), W (Wu et al., 2009). 


\section{MicroRNAs in Endometrial Cancer}

It is not by accident or omission that the discussion of the state of knowledge of the role of miRNAs in cancer presented above did not include a single mention of endometrial cancer. Endometrial cancer is the fourth most common cancer among women worldwide ${ }^{31,32}$ and endometrioid adenocarcinoma accounts for $75 \%-80 \%$ of all endometrial cancers ${ }^{33}$ yet examination of miRNAs in these cancers is minimal in comparison to other cancers.

In the first reported survey, Boren et al. $^{34}$ examined expression of 335 human miRNAs using a hybridization array strategy followed by qPCR validation of selected candidates on the basis of expression levels. Their study sample consisted of 61 fresh frozen endometrial tissues which included 37 endometrial cancers, 20 normal endometrium, and four atypical hyperplasias. They were able to identify a total of thirteen miRNAs as either significantly overexpressed or significantly underexpressed in endometrial cancers as compared to normal endometrium. Their eight over-expressed miRNAs were let-7c, miR-103, miR-106a, miR-107, miR-181a, miR-185, miR210 and $m i R-423$ and their five under-expressed miRNAs were let7i, miR-30c, miR-152, miR-193, and miR-221. In addition to the miRNAs, Boren et al. assessed expression levels of 22,000 messenger RNAs again using a hybridization array strategy. Ninety mRNAs were seen to be differentially expressed in endometrial cancers compared with normal endometrium and, with both sets of expression levels in hand, they were able to link twenty-six differentially expressed mRNAs to their differentially expressed miRNAs by confirming that the mRNAs were predicted targets of one or more of the miRNAs. These miRNA::mRNA pairings have, as yet, to be experimentally confirmed.

$\mathrm{Wu}$ et al. ${ }^{35}$ employed a similar hybridization array strategy to assess differential expression among 469 miRNAs in endometrial cancers. Their survey revealed 17 overexpressed miRNAs and six underexpressed miRNAs in a sample composed of ten endometrioid adenocarcinomas each paired with normal endometrium from the same patients. In addition, they selected six of the 23 miRNAs for subsequent qPCR validation. From the validations they observed that miR205 was eighteen-fold overexpressed in the cancers and that $m i R-449$ and miR-429 were sixteenfold and fifteen-fold over-expressed respectively. In the opposite direction, miR-99b and miR-204 were seen to be less than 0.3-fold expressed in the cancers compared to the normal endometrium.

Using a different approach, that of direct QPCR assessments of miRNA expression levels, Chung et al. ${ }^{36}$ surveyed 157 miRNAs in fresh frozen tissues composed of 22 normal endometrium and 30 endometrioid adenocarcinomas. They reported that thirty of the 157 miRNAs were significantly overexpressed in the cancers and they carried out subsequent validations of 
fourteen (miR-95, miR-103, miR106a, miR-151, miR-155, miR-182, miR-183, miR-194, miR-200a, miR200c, miR-203, miR-205, and miR210). As in the Wu et al. study, the most highly over-expressed microRNA was miR-205 which, in these samples was more than 25fold over-expressed in the adenocarcinomas than in the normal endometrium. Others included $m i R$ 182 (>8-fold), miR-325 (8-fold), and miR-183 (7-fold).

The most ambitious miRNA survey in endometrial cancer to date was recently reported by Hiroki et al. ${ }^{37}$. Using Agilent microRNA hybridization arrays they profiled the expression levels of 470 miRNAs in a sample of seven normal endometrium and 21 endometrial serous adenocarcinomas. This survey identified a total of 66 microRNAs that were overexpressed in the cancers compared to the normal tissues and 54 that were under-expressed in the cancers compared to the normal tissues. Among these, they chose to qPCR validate eight candidate miRNAs that were among those seen to be underexpressed (miR-10b, miR-29b, miR34b, miR-101, miR-133a, miR-133b, miR-152, and miR-411) and one, $m i R-205$, that was very highly overexpressed (>267-fold) in the cancers compared to the normal endometrium.

Taking all four extant studies together and making allowances for differences in the methods used as well as the fact that there is no information on how much the miRNA sets overlapped, comparative
miRNA expression patterns are presented in Figure 2. In spite of the limitations of such a comparison it is interesting to note that seven miRNAs (miR-10a, miR-106a, miR182, miR-200a, miR-200c, miR-203, and miR-205) are significantly overexpressed in three of four surveys and an eighth, miR-210, is significantly over-expressed in all four. Several of these miRNAs, notably miR-182, miR-205 and miR210 , are so-called "cancer miRs" in that they display significant levels of over-expression in numerous cancers. In addition, the five members of the "200 family," miR200a, miR-200b, and miR-429 on human chromosome 1 and miR-200c and miR-141 on human chromosome 12, are well known to be coordinately expressed in cancers $^{38}$. Of these, the one microRNA that has been specifically studied as a validated candidate microRNA in endometrial cancer is miR-200c. Cochrane et al. ${ }^{39}$ examined the potential involvement of $m i R-200 c$ in endometrial cancer from a functional perspective. The transcription factors ZEB1 and ZEB2 (zinc-finger E-box binding homeobox 1 and 2) are known targets of miR200c. ZEB1 is not normally expressed in epithelial cells but, when inappropriately expressed in vitro, it initiates epithelial to mesenchyme transition through repression of E-cadherin and other genes involved in polarity. miR-200c is highly expressed in several welldifferentiated cancer cells, such as the Ishikawa-H endometrial cancer cell line, but displays very low expression in poorly differentiated cells such as the Hec50co 
endometrial cancer cell line (see ref 31 for information on the characteristics of these two cell lines). This is reflected in similarly opposite levels of expression of ZEB1 (Ishikawa low / Hec50co high) and E-cadherin (Ishikawa high / Hec50co negative). Cochrane et al. showed that restoration of expression of miR-200c in Hec50co cells restores E-cadherin expression and decreases ZEB1 expression. This results in a concomitant decline in migration and invasiveness of Hec50co cells to levels resembling the much less aggressive Ishikawa$\mathrm{H}$ cells. Thus, miR-200c has been confirmed to have a direct influence on the behavior of cancer cells.

Another directed miRNA study by Huang et al. $^{40}$ focused on the relationship between a specific microRNA, miR-129-2, and endometrial cancer. The oncogene known as the SRY-related highmobility group box 4 gene, or SOX4, is known to be highly expressed in a number of cancers including endometrial cancer. Overexpression of this gene is related to clinical features such as increased proliferation and poor outcome. Huang et al. (2009) show that expression of miR-129-2 is lost in endometrial cancers when compared to normal endometrium and that SOX4 is a validated miR-129-2 target. When this microRNA was transfected into endometrial cancers cells, including the afore-mentioned Ishikawa H cells, SOX4 expression was suppressed as was proliferative behavior in these cells. Moreover, this effect was also achieved in vitro through demethylation reactivation of
miR-129-2 which led to SOX4 suppression. This last result suggests that hyper-methylationmediated silencing of a microRNA leads to derepression of the SOX4 oncogene. Surprisingly, miR-129-2 was not reported in any of the four miRNA studies discussed here. However, as these studies only listed miRNAs that displayed significant changes in expression levels, there is no way to know if miR-129-2 was among those examined.

Unlike many other cancers, endometrial cancer, along with breast, testicular, and cervical cancers, is significantly influenced by hormones. Cellular growth in the human endometrium is controlled by the antagonistic effects of estrogen and progesterone and endometrial carcinogenesis is linked to high levels of estrogen not ameliorated by the differentiating effects of progesterone ${ }^{41}$. Indeed, it has been shown that expression of the two progesterone receptor isoforms, PRA and PRB, is significantly altered in more aggressive endometrial cancers and that this has profound effects on downstream cellular pathways ${ }^{31,41,42}$. One consequence of disrupted progesterone action in endometrial cancers is the presence of unopposed estrogen. Recently, Klinge $^{43}$ reviewed the effects of estradiol, $E_{2}$, on microRNA expression in various human cancers. Among the miRNAs whose expression was affected by $E_{2}$ are several listed in Figure 2. A few of these, let-7c, let-7i, miR-7, miR-23b, miR-25, miR-27b, miR-151, miR183, miR-195, and miR-423, are sporadically reported but four, miR- 
182, miR-200a, miR-200c, and miR203 , are among those reported in at least three of the four miRNA surveys. However, the studies cited, which focused primarily on breast cancers, showed that the effect of $E_{2}$ on miRNA expression was cell-typedependent. Thus, it remains to be seen what effect if any both progesterone receptor changes and unopposed estrogen might have on miRNA expression in endometrial cancer.

As noted above, miRNA studies in endometrial cancer are few in number yet these few studies have already identified a number of candidate miRNAs for more detailed analysis. One of these, miR-200c, has proven to be very informative with regard to one of the cancer hallmarks outlined in the beginning of this review- the ability of cancer cells to colonize other regions of the body. It is this interplay between carefully designed miRNA surveys and controlled studies of candidates identified in those surveys that will lead to a much greater understanding of the role played by small regulatory RNAs in endometrial cancers.

\section{Envoi}

At the beginning of this paper it was noted that cancer cells behave differently than do normal cells and that these differences in behavior result from cancer cells essentially re-writing the rules that apply to normal cells existing in equilibrium. The principle means that cells use to regulate their behavior is through appropriate transcription of genes into proteins. Cancer cells have been shown to reprogram gene transcription to their advantage. The discovery of microRNAs as a complex and powerful posttranscriptional level of gene expression regulation has introduced the possibility that cancer cells alter miRNA expression to assist in carrying out that reprogramming. Indeed, it has been suggested that a global reduction of miRNA levels is emerging as an additional hallmark of cancer ${ }^{44}$. Such global effects can be accomplished in a number of ways including the activation of cancer-associated transcription factors like p53 and Myc which are known to have direct effects on miRNAs of the miR-34 family (p53) and miR-17 cluster (Myc). Chang et al. ${ }^{45}$ have further shown that activation of Myc in cancer could directly reprogram the wider miRNA transcriptome. Other potential means of accomplishing miRNA reprogramming result from the massive genetic alterations known to occur in cancer cells ${ }^{18,46}$ and from specific alterations of the miRNA processing machinery itself ${ }^{47,48}$. Thus, continued detailed studies of miRNAs in cancers will shed new light on the nature of cellular reprogramming and lead to new and more efficient ways to attack cancers in general $^{44}$ and, from our perspective, endometrial cancers in particular, in the clinic. 


\section{References}

1. Hanahan D, Weinberg RA. The hallmarks of cancer. Cell. 2000 Jan 7;100(1):57-70.

2. Lee RC, Feinbaum RL, Ambros V. The $C$. elegans heterochronic gene lin- 4 encodes small RNAs with antisense complementarity to lin-14. Cell. 1993 Dec 3;75(5):843-54.

3. Wightman B, Ha I, Ruvkun G. Posttranscriptional regulation of the heterochronic gene lin-14 by lin-4 mediates temporal pattern formation in C. elegans. Cell. 1993 Dec 3;75(5):855-62.

4. Griffiths-Jones S, Saini HK, van Dongen S, Enright AJ. miRBase: tools for microRNA genomics. Nucleic Acids Res. 2008 Jan;36(Database issue):D154-8.

5. Bartel DP. MicroRNAs: target recognition and regulatory functions. Cell. 2009 Jan 23;136(2):215-33.

6. Kim VN, Han J, Siomi MC. Biogenesis of small RNAs in animals. Nat Rev Mol Cell Biol. 2009 Feb;10(2):126-39.

7. Friedman RC, Farh KK, Burge CB, Bartel DP. Most mammalian mRNAs are conserved targets of microRNAs. Genome Res. 2009 Jan;19(1):92-105.

8. Lewis BP, Burge CB, Bartel DP. Conserved seed pairing, often flanked by adenosines, indicates that thousands of human genes are microRNA targets. Cell. 2005 Jan 14;120(1):15-20.

9. Sun G, Li H, Rossi JJ. Sequence context outside the target region influences the effectiveness of miR223 target sites in the RhoB 3'UTR. Nucleic Acids Res. 2010 Jan;38(1):239-52.

10. Cai X, Hagedorn $\mathrm{CH}$, Cullen BR. Human microRNAs are processed from capped, polyadenylated transcripts that can also function as mRNAs. RNA. 2004

Dec;10(12):1957-66.

11. Han J, Lee Y, Yeom KH, Kim YK, Jin $\mathrm{H}$, Kim VN. The Drosha-DGCR8 complex in primary microRNA processing. Genes Dev. 2004 Dec 15;18(24):3016-27.

12. Yi R, Qin Y, Macara IG, Cullen BR. Exportin-5 mediates the nuclear export of pre-microRNAs and short hairpin RNAs. Genes Dev. 2003 Dec 15;17(24):3011-6.

13. Chendrimada TP, Gregory RI, Kumaraswamy E, Norman J, Cooch N, Nishikura K, Shiekhattar R. TRBP recruits the Dicer complex to Ago2 for microRNA processing and gene silencing. Nature. 2005 Aug 4;436(7051):740-4.

14. Haase $A D$, Jaskiewicz $L$, Zhang $H$, Lainé S, Sack R, Gatignol A, Filipowicz W. TRBP, a regulator of cellular PKR and HIV-1 virus expression, interacts with Dicer and functions in RNA silencing. EMBO Rep. 2005 Oct;6(10):961-7.

15. Zhang B, Pan X, Cobb GP, Anderson TA. microRNAs as oncogenes and tumor suppressors. Dev Biol. 2007 Feb 1;302(1):1-12.

16. Gartel AL, Kandel ES. miRNAs: Little known mediators of oncogenesis. Semin Cancer Biol. 2008 Apr;18(2):103-10.

17. Ventura A, Jacks T. MicroRNAs and cancer: short RNAs go a long way. Cell. 2009 Feb 20;136(4):586-91.

18. Calin GA, Sevignani C, Dumitru CD, Hyslop T, Noch E, Yendamuri S, Shimizu M, Rattan S, Bullrich F, Negrini M, Croce CM. Human microRNA genes are frequently located at fragile sites and genomic regions involved in cancers. Proc Natl Acad Sci U S A. 2004 Mar 2;101(9):2999-3004. 
19. Ciafrè $S A$, Galardi $S$, Mangiola A, Ferracin M, Liu CG, Sabatino G, Negrini M, Maira G, Croce CM, Farace MG. Extensive modulation of a set of microRNAs in primary glioblastoma. Biochem Biophys Res Commun. 2005 Sep 9;334(4):13518.

20. Calin GA, Dumitru CD, Shimizu M, Bichi R, Zupo S, Noch E, Aldler H, Rattan S, Keating M, Rai K, Rassenti L, Kipps T, Negrini M, Bullrich F, Croce CM. Frequent deletions and down-regulation of micro- RNA genes miR15 and miR16 at 13q14 in chronic lymphocytic leukemia. Proc Natl Acad Sci U S A. 2002 Nov 26;99(24):15524-9.

21. Murakami Y, Yasuda T, Saigo K, Urashima T, Toyoda H, Okanoue T, Shimotohno K. Comprehensive analysis of microRNA expression patterns in hepatocellular carcinoma and non-tumorous tissues. Oncogene. 2006 Apr 20;25(17):2537-45.

22. Takamizawa J, Konishi H, Yanagisawa K, Tomida S, Osada $\mathrm{H}$, Endoh $\mathrm{H}$, Harano $\mathrm{T}$, Yatabe $\mathrm{Y}$, Nagino M, Nimura $Y$, Mitsudomi T, Takahashi T. Reduced expression of the let-7 microRNAs in human lung cancers in association with shortened postoperative survival. Cancer Res. 2004 Jun 1;64(11):3753-6.

23. Hayashita $\mathrm{Y}$, Osada $\mathrm{H}$, Tatematsu $\mathrm{Y}$, Yamada $\mathrm{H}$, Yanagisawa $\mathrm{K}$, Tomida S, Yatabe Y, Kawahara K, Sekido Y, Takahashi T. A polycistronic microRNA cluster, miR-17-92, is overexpressed in human lung cancers and enhances cell proliferation. Cancer Res. 2005 Nov 1;65(21):9628-32.

24. Eis PS, Tam W, Sun L, Chadburn A, Li Z, Gomez MF, Lund E, Dahlberg JE. Accumulation of miR-155 and BIC RNA in human $B$ cell lymphomas. Proc Natl Acad Sci U S A. 2005 Mar 8;102(10):3627-32.

25. He L, Thomson JM, Hemann MT, Hernando-Monge E, Mu D, Goodson S, Powers S, CordonCardo C, Lowe SW, Hannon GJ, Hammond SM. A microRNA polycistron as a potential human oncogene. Nature. 2005 Jun 9;435(7043):828-33.

26. Jung M, Mollenkopf HJ, Grimm C, Wagner I, Albrecht M, Waller T, Pilarsky C, Johannsen M, Stephan $\mathrm{C}$, Lehrach $\mathrm{H}$, Nietfeld $\mathrm{W}$, Rudel $\mathrm{T}$, Jung K, Kristiansen G. MicroRNA profiling of clear cell renal cell cancer identifies a robust signature to define renal malignancy. J Cell Mol Med. 2009 Sep;13(9B):3918-28.

27. Saito $Y$, Suzuki H, Hibi T. The role of microRNAs in gastrointestinal cancers. J Gastroenterol. 2009;44 Suppl 19:18-22.

28. Spizzo R, Nicoloso MS, Croce CM, Calin GA. SnapShot: MicroRNAs in Cancer. Cell. 2009 May 1;137(3):586-586.e1.

29. Scott GK, Goga A, Bhaumik D, Berger CE, Sullivan CS, Benz CC. Coordinate suppression of ERBB2 and ERBB3 by enforced expression of micro-RNA miR $125 \mathrm{a}$ or miR125b. J Biol Chem. 2007 Jan 12;282(2):1479-86.

30. Mendell JT. miRiad roles for the miR-17-92 cluster in development and disease. Cell. $2008 \mathrm{Apr}$ 18;133(2):217-22.

31. Albitar L, Pickett G, Morgan M, Davies S, Leslie KK. Models representing type I and type II human endometrial cancers: Ishikawa $\mathrm{H}$ and $\mathrm{Hec50co}$ cells. Gynecol Oncol. 2007 Jul;106(1):5264.

32. Jemal A, Siegel R, Ward E, Murray $\mathrm{T}, \mathrm{Xu}$ J, Thun MJ. Cancer statistics, 
2007. CA Cancer J Clin. 2007 JanFeb;57(1):43-66.

33. Pecorelli S, Pasinetti B, Angioli R, Favalli G, Odicino F. Systemic therapy for gynecological neoplasms: ovary, cervix, and endometrium. Cancer Chemother Biol Response Modif. 2005;22:51544.

34. Boren T, Xiong Y, Hakam A, Wenham R, Apte S, Wei Z, Kamath $\mathrm{S}$, Chen DT, Dressman $\mathrm{H}$, Lancaster JM. MicroRNAs and their target messenger RNAs associated with endometrial carcinogenesis. Gynecol Oncol. 2008 Aug;110(2):206-15.

35. Wu W, Lin Z, Zhuang Z, Liang X. Expression profile of mammalian microRNAs in endometrioid adenocarcinoma. Eur J Cancer Prev. 2009 Feb;18(1):50-5.

36. Chung TK, Cheung TH, Huen NY, Wong KW, Lo KW, Yim SF, Siu NS, Wong YM, Tsang PT, Pang MW, Yu MY, To KF, Mok SC, Wang VW, Li C, Cheung AY, Doran G, Birrer MJ, Smith DI, Wong YF. Dysregulated microRNAs and their predicted targets associated with endometrioid endometrial adenocarcinoma in Hong Kong women. Int J Cancer. 2009 Mar 15;124(6):1358-65.

37. Hiroki E, Akahira J, Suzuki F, Nagase S, Ito K, Suzuki T, Sasano $\mathrm{H}$, Yaegashi N. Changes in microRNA expression levels correlate with clinicopathological features and prognoses in endometrial serous adenocarcinomas. Cancer Sci. 2010 Jan;101(1):241-9.

38. Vrba L, Jensen TJ, Garbe JC, Heimark RL, Cress AE, Dickinson S, Stampfer MR, Futscher BW. Role for DNA methylation in the regulation of miR-200c and miR-141 expression in normal and cancer cells. PLoS One. 2010 Jan 13;5(1):e8697.

39. Cochrane DR, Spoelstra NS, Howe EN, Nordeen SK, Richer JK. MicroRNA 200c mitigates invasiveness and restores sensitivity to microtubule targeting chemotherapeutic agents. Mol Cancer Ther. 2009;8(5):1055-66.

40. Huang YW, Liu JC, Deatherage DE, Luo J, Mutch DG, Goodfellow PJ, Miller DS, Huang TH. Epigenetic repression of microRNA-129-2 leads to overexpression of SOX4 oncogene in endometrial cancer. Cancer Res. 2009 Dec 1;69(23):9038-46.

41. Dai $D$, Albitar L, Nguyen $T$, Laidler LL, Singh M, Leslie KK. A therapeutic model for advanced endometrial cancer: systemic progestin in combination with local adenoviral-mediated progesterone receptor expression. Mol Cancer Ther. 2005 Jan;4(1):169-75.

42. Kumar NS, Richer J, Owen G, Litman E, Horwitz KB, Leslie KK. Selective down-regulation of progesterone receptor isoform $B$ in poorly differentiated human endometrial cancer cells: implications for unopposed estrogen action. Cancer Res. 1998 May 1;58(9):1860-5.

43. Klinge CM. Estrogen Regulation of MicroRNA Expression. Curr Genomics. 2009 May;10(3):169-83.

44. Davalos V, Esteller M. MicroRNAs and cancer epigenetics: a macrorevolution. Curr Opin Oncol. 2010 Jan;22(1):35-45.

45. Chang TC, Yu D, Lee YS, Wentzel EA, Arking DE, West KM, Dang CV, Thomas-Tikhonenko A, Mendell JT. Widespread microRNA repression by Myc contributes to tumorigenesis. Nat Genet. 2008 Jan;40(1):43-50. 
46. Zhang L, Huang J, Yang N, Greshock J, Megraw MS, Giannakakis A, Liang S, Naylor TL, Barchetti A, Ward MR, Yao G, Medina A, O'brien-Jenkins A, Katsaros D, Hatzigeorgiou A, Gimotty PA, Weber BL, Coukos G. microRNAs exhibit high frequency genomic alterations in human cancer. Proc Natl Acad Sci U S A. 2006 Jun 13;103(24):9136-41.

47. Muralidhar B, Goldstein LD, Ng G, Winder DM, Palmer RD, Gooding EL, Barbosa-Morais NL, Mukherjee G, Thorne NP, Roberts I, Pett MR, Coleman N. Global microRNA profiles in cervical squamous cell carcinoma depend on Drosha expression levels. J Pathol. 2007 Aug;212(4):368-77.

48. Merritt WM, Lin YG, Han LY, Kamat AA, Spannuth WA, Schmandt R, Urbauer D, Pennacchio LA, Cheng JF, Nick AM, Deavers MT, MouradZeidan A, Wang $\mathrm{H}$, Mueller $\mathrm{P}$, Lenburg ME, Gray JW, Mok S, Birrer MJ, Lopez-Berestein G, Coleman RL, Bar-Eli M, Sood AK. Dicer, Drosha, and outcomes in patients with ovarian cancer. N Engl J Med. 2008 Dec 18;359(25):264150. 